\title{
Preliminary study about microbial contamination of metallic brackets in orthodontic practice
}

\author{
Cristina Nicoleta Mihai ${ }^{1}$, Gabriel Ciochinda ${ }^{1}$, Claudia Camelia Burcea ${ }^{1}$, \\ Mihai Burlibasa ${ }^{1}$, Viorel Stefan Perieanu', Madalina Violeta Perieanu', Oana Eftene', \\ Iuliana Babiuc ${ }^{1}$, Ruxandra Stanescu', Olivia Popoviciu', Madalina Malita', \\ Radu Costea', Magdalena Natalia Dina', Oana-Cella Andrei', \\ Liliana Burlibasa ${ }^{2}$, Ileana Ionescu ${ }^{1}$ \\ 1"Carol Davila" University of Medicine and Pharmacy, Bucharest, Romania \\ ${ }^{2}$ Faculty of Biology, University of Bucharest, Romania
}

\begin{abstract}
Introduction. Infectious risk in orthodontic practice is a real risk and involves problems both for the medical team of orthodontics and dental-facial orthopedics and for patients.

Purpose. In this material we tried to highlight both the microbial load taken from the level of metal breaches existing in the oral cavity but also the effect of mouthwashes with wide commercial use, on the different categories of germs isolated from these surfaces.

Material and method. Microbial harvesting was carried out at different stages of the consultation and periodic examination in order to establish the effect that different substances have on reducing microbial load.

Results and discussion. The results obtained for each stage and study group are graphically exemplified for a better understanding of the studied problem.

Conclusions. The efficiency of the substances for removing the bacterial load is considerable but the replacement of disinfectants due to their toxicity and aggressiveness must be considered.
\end{abstract}

Keywords: metal brackets, microbial load, mouthwashes

\section{INTRODUCTION}

It is known about oral cavity that this is a septic cavity both through the connection with external environment, but also through food and respiratory intake. Microorganisms from the oral cavity are organized in large groups (or colonies) of great complexity, from the first hours of life of the newborn. But contamination and then microbial colonization are gradually and selectively carried out with various microorganisms, which will very quickly become characteristic of the anatomical territory that harbors them (1-5).

Microbiology research has shown through extensive studies that the adult human body can host
100 times more living bacteria, pathogenic and non-pathogenic, than the number of cells in the human body. Specifically, in the oral cavity we find a very large variety of germs, because here there are ideal conditions for the development and multiplication of microorganisms: we discuss not only about the excess nutrients, but also about a favorable $\mathrm{pH}$, humidity and an ideal temperature, about $37^{\circ} \mathrm{C}(6-13)$.

The flora of the oral cavity is a polymorphic one and has a double origin, as follows (1-5):

- Exogenous: from air, water, food, from the skin;

- Endogenous: from the patients or carriers, through the fluids existing in the oral cavity 
(saliva, blood etc.) or through secretions from the infected dental pulp and/or from the apical, marginal or periodontal inflammatory processes.

\section{PURPOSE}

Starting from the notions presented in the introductory part of this material, we can say that the objectives of conducting this study are those of carrying out and presenting standardized procedures for organizing and conducting the stages of a clinical and microbiological examination of accessories used in orthodontics and dentofacial orthopedics, in various situations. Specifically, we are discussing about dental brackets, mandatory accessories in making of a fixed orthodontic appliance and that we find cemented on the teeth on which these fixed orthodontic devices are applied. These fixed orthodontic accessories, dental brackets, can be made from several types of materials, such as ceramic, metal alloys and sapphire (14). In our case, the study was carried out on metal brackets (they are made of stainless steel), and, depending on the results obtained, the study will be extended both on other types of materials from which the brackets are made, as well as on other accessories specific to orthodontics and dentofacial orthopedics.

In this context, we conducted a mixed study, both with a clinical component of the orthodontic and dentofacial orthopedics office and with a microbiology laboratory component, regarding the contamination of some metal brackets, going through several stages, which we will describe next.

\section{MATERIALS AND METHODS}

In order to carry out this study, the microbial contamination of some metal brackets (they are made of stainless steel) was monitored, cemented in the oral cavity of some patients, children, adolescents, but also adults, carriers of fixed dental appliances (fixed orthodontic appliances), in several stages performed during the same treatment session. We discuss about 15 patients with age between 9 and 42 years (children, adolescents and adults), with different hygiene index, who presented for specialized treatment in the offices of orthodontics and dentofacial orthopedics, where we carry out our activity (in the Municipality of Bucharest), for specialized treatment, that is, controls after the application of fixed dental appliances (fixed orthodontic appliances). The gender distribution of patients was as follows: 7 subjects $(46.67 \%)$ were fe- male, while 8 patients $(53.33 \%)$ included in the study were male (Fig. 1)

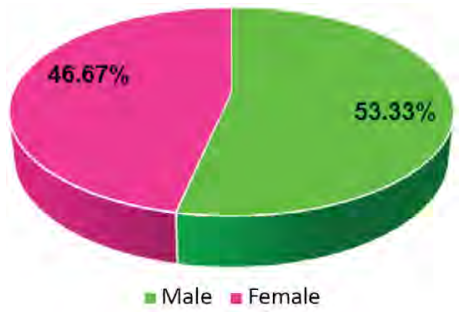

FIGURE 1. Gender distribution of the patients included in the study

Microbial harvesting was performed strictly on the surface of the cemented metal brackets on the teeth in the oral cavity of the patients, from a number of 15 patients wearing fixed dental appliances, in a single specialized treatment session, having gone through several stages:

1. The patient was placed on the dentistry chair, and the first microbial sampling was performed during the oral cavity inspection.

2. Then, the patient was instructed to rinse the oral cavity thoroughly with plain water for $15 \mathrm{sec}$ onds. After this rinsing, a second microbial sampling was performed on the surface of the metal brackets.

3 . In the third stage, the professional orthodontist performed the professional scaling and brushing, after which the third microbial sampling was performed on the surface of the metal brackets.

4. The last stage consisted of rinsing with mouthwash, about 10 minutes after completing the professional scaling and brushing, for about 10-15 seconds. After the completion of this stage, the sampling with the number 4 from the surface of the metal brackets was performed. The mouthwashes had as basic antiseptic substances chlorhexidine (biguanidic compound), ethyl alcohol (compound from the alcohol class) and cetylpyridinium chloride (it is part of the quaternary ammonium salt group).

Basically, after the completion of the 3rd stage (professional scaling and brushing), the group of 15 patients was divided into 3 groups of 5 people each, as follows:

- Group I has rinsed with chlorhexidine mouthwash;

- Group II has rinsed with ethyl alcohol mouthwash;

- Group III has rinsed with cetylpyridinium chloride mouthwash.

In order to carry out the microbial sampling process, the informed consent of the patients was ob- 
tained if they were majors, or of their parents, if they were minors. The entire study was subject to anonymity. Although each patient had the opportunity to withdraw at any time during the study, no subject expressed this desire.

In this microbiology study, the presence of Enterobacteriaceae (Escherichia coli, Citrobacter, Proteus, Klebsiella), coagulase positive Staphylococcus, hemolytic Streptococcus and fungi (Candida albicans) was monitored. The determinations were made using the specific means of the microbiology laboratory. Microbiological harvesting in all the aforementioned steps was done using the buffer method, a process consisting of wiping with a sterile, moistened cotton wool of the surface to be investigated (in our case, the metal brackets), followed by its rinsing in a diluent liquid, and highlighting the germs on the appropriate culture media. Sampling for microbiological analysis was performed, in compliance with the aseptic prescriptions, in order to avoid any possibility of their further contamination. The transport of the samples to the microbiology laboratory with which we collaborated in this case was done quickly, in maximum 4 hours from the moment of collection.

\section{RESULTS AND DISCUSSION}

Following the analysis, the next aspects were found, reported for the whole group of 15 patients.

After the first stage, when the first microbial harvest was performed during the inspection of the oral cavity, by the specialist in orthodontics and dentofacial orthopedics, we had the following situation: Enterobacteriaceae (Escherichia coli, Citrobacter, Proteus, Klebsiella) were present at 12 patients $(80 \%)$, coagulase positive Staphylococcus were present in 1 patient $(6.67 \%)$, fungi or more specifically Candida albicans were present in 11 patients (73.33\%), hemolytic Streptococcus were present in 1 patient (6.67\%) (Fig. 2).

After the second stage, namely the energic rinsing for 15 seconds with plain water, the following situation was highlighted: Enterobacteriaceae (Escherichia coli, Citrobacter, Proteus, Klebsiella) were present in 10 patients $(66.66 \%)$ and fungi or more specifically Candida albicans were present in a number of 9 patients (60\%). No coagulase positive Staphylococcus and hemolytic Streptococcus have been detected (Fig. 3).

After the third stage, after performing the professional scaling and brushing, we had the following situation: Enterobacteriaceae (Escherichia coli, Citrobacter, Proteus, Klebsiella) were present in a number of 4 patients $(26.66 \%)$ and fungi or more precisely Candida albicans were present in 3 patients $(20 \%)$. No coagulase positive Staphylococcus and hemolytic Streptococcus have been detected (Fig. 4).

After the fourth stage, after rinsing with mouthwash, for about 10 minutes after completing the professional scaling and brushing, for about 10-15 seconds, we observed the following aspects:

a. For Group 1, after rinsing with chlorhexidine mouthwash, enterobacteriaceae (Escherichia coli, Citrobacter, Proteus, Klebsiella) were identified in 2 patients (13.33\%) and fungi or more precisely Candida albicans were present in 1 patient $(6.66 \%)$ (Fig. 5).

b. For Group 2, after rinsing with ethyl alcohol mouthwash, Enterobacteriaceae (Escherichia coli, Citrobacter, Proteus, Klebsiella) were identified in 1 patient $(6.66 \%)$ and fungi or more specifically Candida albicans were present in 2 patients (13.33\%) (Fig. 6).

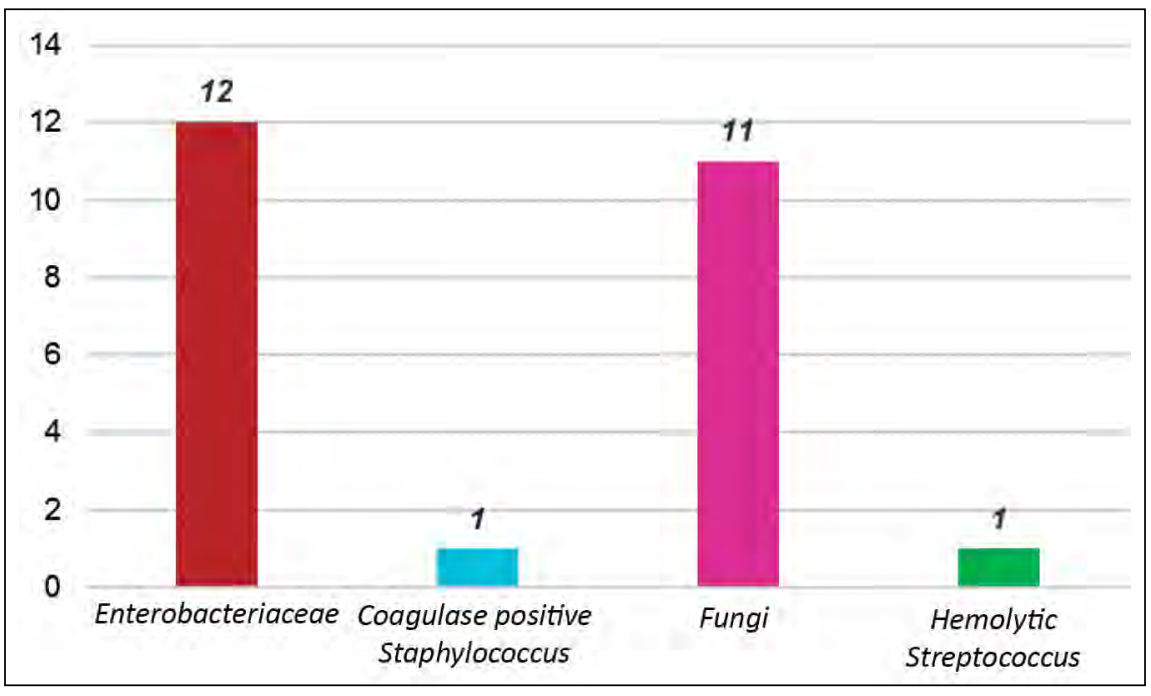

FIGURE 2. Microbial distribution according to the number of patients after the first stage of the treatment session 

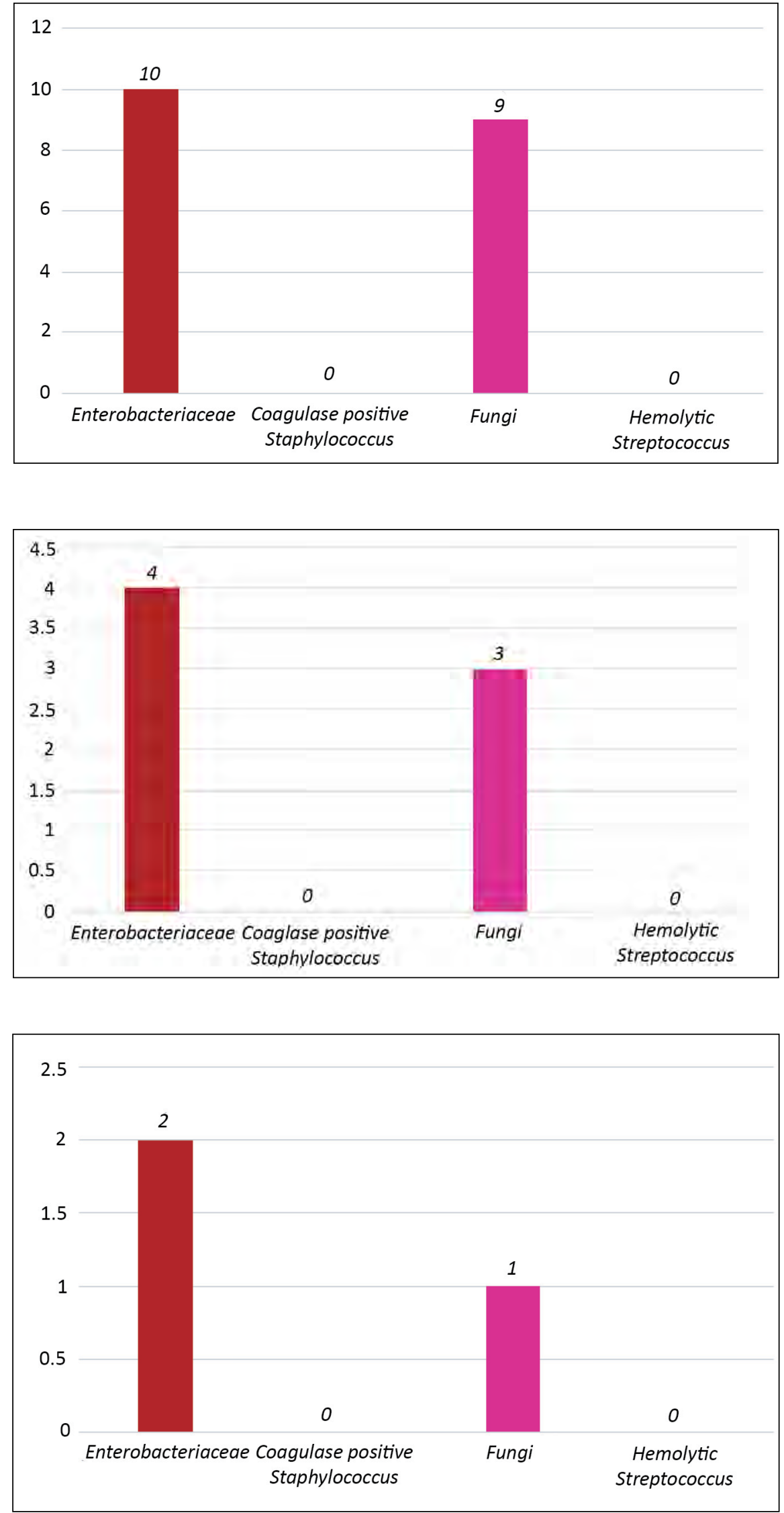

FIGURE 3. Microbial distribution according to the number of patients after the second stage of the treatment session

FIGURE 4. Microbial distribution according to the number of patients after the third stage of the treatment session (after professional scaling and brushing)
FIGURE 5. Microbial distribution according to the number of patients after the fourth stage of the treatment session (after rinsing with chlorhexidine mouthwash) c. For Group 3, after rinsing with cetylpyridinium chloride mouthwash, Enterobacteriaceae (Escherichia coli, Citrobacter, Proteus, Klebsiella) were identified in 1 patient $(6.66 \%)$ and fungi or more precisely Candida albicans were also present in 1 patient (6.66\%) (Fig. 7). 

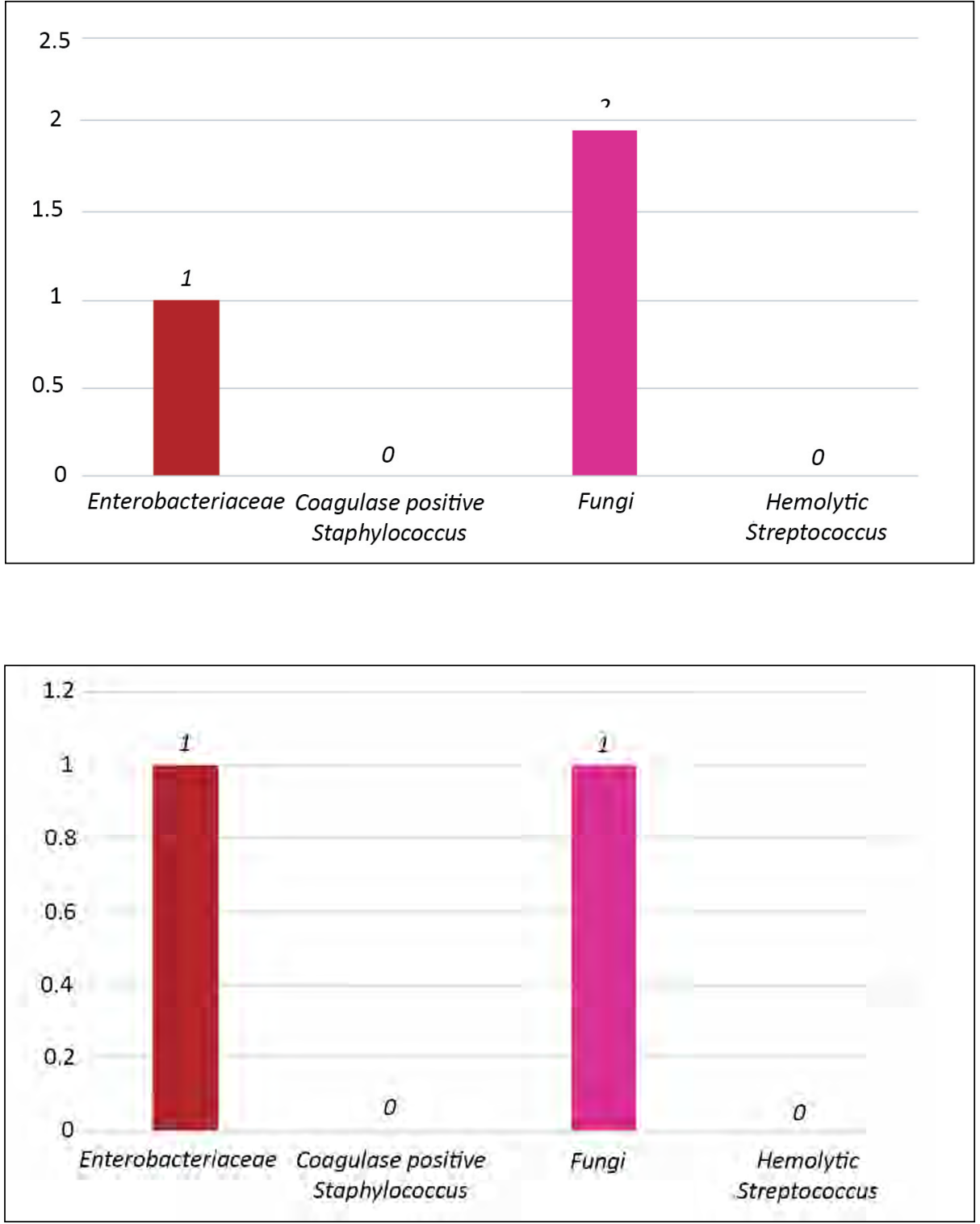

FIGURE 6. Microbial distribution according to the number of patients after the fourth stage of the treatment session (after rinsing with ethyl alcohol based mouth wash)
FIGURE 7. Microbial distribution according to the number of patients after the fourth stage of the treatment session (after rinsing with cetylpyridinium chloride mouthwash).
The results obtained from this study are in agreement with the results obtained in other studies regarding the effect of chlorhexidine (15-18), ethyl alcohol (19-21) or cetylpyridine chloride (22-24) on the control of bacterial contamination of the brackets in patients undergoing orthodontic treatments with fixed appliances.

\section{CONCLUSIONS}

These auxiliary elements used in orthodontics and dentofacial orthopedics, which are the metal brackets, cemented on the teeth, represent extremely retentive elements for the dental microbial plaque, therefore, in addition to the regular specialized consultation, it must be performed for the professional scaling and brushing, at predetermined time intervals.
All mouthwashes, regardless of the basic substance (chlorhexidine, ethyl alcohol, cetylpyridinium chloride), have proven their effectiveness in a similar way over all categories of isolated microorganisms.

It is necessary to insist on the fact that, due to their toxicity and aggressiveness, these disinfectant substances that enter the composition of the mouthwashes and which are part of the categories of disinfectants already established (biguanides, alcohols, quaternary ammonium salts), will be gradually replaced with certain herbal compounds, which have strong antiseptic properties: sage, pot marigold, peppermint, chamomile, sea buckthorn etc.

All patients with fixed dental appliances should be trained very effectively by the orthodontic and dentofacial orthopedic staff, in maintaining proper hygiene, through proper self-cleaning techniques. 
It is necessary a permanent training of specialized medical personnel, regarding the appearance and use of new specific materials on the Romanian market of dental products.

\section{REFERENCES}

1. Burlibașa M, Dumitru SG, Tănase G, Sfarghiu L. Flora cavității bucale - element de contaminare directă și indirectă în reabilitarea implanto-protetică. În: Trăistaru T, Burlibașa M, lonescu I. Progrese în medicina dentară, Vol. III, București: Ed. Ars Docendi, 2012: 48-63.

2. Burlibașa $\mathrm{M}$, lonescu I, Bodnar D et al. Aspecte teoretice și practice ale formării, dezvoltării și combaterii biofilmelor microbiene în medicina dentară. Medicina Modernă. 2008; 15(10):544-547.

3. Burlibașa L, Burlibașa M, Ionescu I. Microflora cavității bucale - posibil factor de risc infecțios în practica stomatologică. Sibiul Medical. lanuarie-Martie 2003; 14(1):43-45.

4. Lazăr V. Aderența microbiană. Bucureșri: Ed. Academiei Române, 2003.

5. Nolte AW. Oral Microbiology with Basic Microbiology and Immunology 4th Edition. St. Louis: CV Mosby Company, 1982.

6. Burlibașa M, Muntianu L, Tănase $G$ et al. Study on microbial contamination of biomaterials in medical practice. Metalurgia International. 2010; 15 (Spec Issue)(2):163-166.

7. Tănase $G$, Burlibașa $M$, Muntianu L et al. Testing the antibacterial potential of biomaterials in medical practice. Metalurgia International. 2010; 15(Spec Issue)(2):160-162.

8. Burlibașa M, Tănase $G$, Muntianu L et al. Quality of life, a multidisciplinary concept with economic and social impacts in medical practice. Metalurgia International. 2010; 15(Spec Issue) (4):88-90.

9. Ispas DC, Eftene OA, Burlibașa M et al. Implications of titanium in orthodontics and dental facial orthopedics. Metalurgia International. 2011; 16(10):72-74.

10. Burlibașa M, Cernușcă-Mițariu M, Burcea CC et al. Halogen compounds - theoretical, physiological and practical aspects regarding the decontamination, disinfection and sterilisation of intsruments and biomaterials in dental medicine practice. Metalurgia International. 2012; 18(Spec Issue 3):54-57.

11. Burlibașa M, Cernușcă-Mițariu M, Cernușcă-Mițariu S et al. Theoretical and practical aspects related to biomaterials decontamination in dental medicine (with reference to dental prosthetics). Metalurgia International. 2013; 18(4):261-267.

12. Burlibasa L, Domnariu C. Epigenetic landscape of human diseases. Acta Medica Transilvanica. 2018; 23(2):33-37.

13. Bodnar DC, Burlibașa L, Vârlan C et al. Mercury, biocompatibility and its impact on environment. Metalurgia International. 2009; 14:95-100.

14. Cristache $\mathrm{CM}$, Burlibașa $\mathrm{M}$, Cristache $\mathrm{G}$ et al. Zirconia and its biomedical applications. Metalurgia International. 2011; 16(7):18-23.

\section{Acknowledgement}

In this article, all the authors have equal contribution with the first author.

Conflict of interest: none declared Financial support: none declared

15. Samar MAB, Mona AA, Ahmet SB et al. Effects of chlorhexidine (gel) application on bacterial levels and orthodontic brackets during orthodontic treatment. J.Oral Scien. 2016; 58(1):35-42.

16. Jurisic $\mathrm{S}$, Kozomara $\mathrm{D}$, Juric $\mathrm{H}$ et al. The influence of different types of brackets and efficacy of two chlorhexidine mouthwashes on oral hygiene and the incidence of white spot lesions in adolescents during the orthodontic therapy. Psychiatr Danub. 2016; 28 (Suppl 2): 247-252.

17. Enita N, Dzemidzic V, Tiro A, Hadzic S. Antimicrobial activity of chlorhexidine in patients with fixed orthodontic appliances. Brazilian Journal of Oral Sciences, 2015: 10(2), 79-82.

18. Shah SS, Nambiar S, Kamath D et al. Comparative Evaluation of Plaque Inhibitory and Antimicrobial Efficacy of Probiotic and Chlorhexidine Oral Rinses inOrthodontic Patients: A Randomized Clinical Trial. Hindawi Intl J Dent. 2019.

19. Omidkhoda M, Poosti M, Sahebnasagh Z et al. Effects of three different mouthwashes on the surface characteristics of nickel-titanium and Stainless steel archwires in orthodontics. Journal of Dental Materials and Techniques, 2017; 6(1):19-26.

20. Santana W, Thahar B, Mardiati E, Salim J. The effect of alcoholic mouthwash, non-alcoholic mouthwash and artificial saliva towards the power chains force decay. Padjadjaran Journal of Dentistry 2017; 29(3):195-201.

21. Haas AN, Pannuti CM, Andrade AK et al. Mouthwashes for the control of supragingival biofilm and gingivitis in orthodontic patients: Evidence-based recommendations for clinicians. Braz Oral Res. 2014 Jul 11;28(spe):1-8.

22. Pahwa N, Kumar A, Gupta S. Short term clinical effectiveness of a $0.07 \%$ cetylpyridinium chloride mouth rinse in patients undergoing fixed orthodontic appliance treatment. Saudi Dent J. 2011 Jul;23(3):135-41.

23. Albert-Kiszely A, Pjetursson BE, Salvi GE et al. Comparison of the Effects of Cetylpyridinium Chloride With an Essential Oil Mouth Rinse on Dental Plaque and Gingivitis - A Six-Month Randomized Controlled Clinical Trial. J Clin Periodontol. 2007; 34(8):658-667.

24. Yang SJ, Han SH, Lee AR et al. Evaluation of antimicrobial effects of commercial mouthwashes utilized in South Korea. BMB Rep. 2015;48(1):42-47. 